\title{
Effects of post-exercise recovery methods on exercise-induced hormones and blood fatigue factors: a systematic review and meta-analysis
}

\author{
Peifei Gu ${ }^{1 \#}$, Linhuan Zhang ${ }^{2 \#}$, Ximing Zheng', Xin'an Zhang ${ }^{1}$ \\ ${ }^{1}$ College of Kinesiology, Shenyang Sport University, Shenyang, China; ${ }^{2}$ College of Sports Training, Shenyang Sport University, Shenyang, China \\ Contributions: (I) Conception and design: P Gu, X Zhang; (II) Administrative support: X Zhang; (III) Provision of study materials or patients: X \\ Zheng; (IV) Collection and assembly of data: X Zheng; (V) Data analysis and interpretation: P Gu, L Zhang; (VI) Manuscript writing: All authors; (VII) \\ Final approval of manuscript: All authors. \\ "These authors contributed equally to this work. \\ Correspondence to: Xin'an Zhang. College of Kinesiology, Shenyang Sport University, Shenyang, China. Email: zhangxa2725@163.com.
}

Background High-intensity exercise consumes a large amount of energy and tends to induce post-exercise fatigue. Promoting physical and psychological recovery after exercise can enable individuals to perform better in subsequent training or competitions and reduce the risk of injury. This study aims to investigate the effects of post-exercise recovery methods on exercise-induced hormones and blood fatigue factors.

Methods: PubMed, Embase and Web of Science databases were queried to collect literature on the correlation between post-exercise recovery methods and the expression of exercise-induced hormones and blood fatigue factors. The search time ranged between inception to July 2020. Stata (version 15.0) was used for meta-analysis.

Results: A total of 10 studies were included, involving the data of 278 cases. Among these, 148 people were placed in the study group and assigned active post-exercise recovery measures while 130 people were placed in the control group and assigned no post-exercise recovery measures. The results of this meta-analysis showed that there was significant difference between the study group and the control group [relative risk $(\mathrm{RR})=15.62,95 \%$ confidence interval $(\mathrm{CI}): 3.25,75.06, \mathrm{P}<0.05]$. The subgroup analysis on the effect of active and passive recovery on the blood lactate concentration (BLC) and creatine kinase (CK) concentration revealed that the CK concentration [standardized mean difference (SMD) $=-0.76,95 \% \mathrm{CI}:-1.47,-0.04]$ and BLC (SMD =-1.16, 95\% CI: -2.30, -0.02) were significantly lower in the study group compared with the control group. Further analysis on the effect of different post-exercise recovery methods on the BLC and CK concentrations indicated that BLC (SMD =-1.16, 95\% CI: -2.30, -0.02) was significantly lower in the group with cold water immersion compared with the control group, while there was no significant difference in the changes of CK concentration. Additionally, food supplementation was shown to reduce CK concentration (SMD $=-1.16,95 \%$ CI: $-4.69,2.36)$.

Conclusions: Recovery measures after high-intensity exercise can accelerate the reduction of BLC and the activity and concentration of CK, thus helping the body quickly return to a pre-exercise state.

Keywords: Exercise recovery; cold water immersion; creatine kinase (CK); blood lactate concentration (BLC)

Submitted Sep 23, 2020. Accepted for publication Jan 11, 2021.

doi: 10.21037/apm-20-2409

View this article at: http://dx.doi.org/10.21037/apm-20-2409 


\section{Introduction}

The improvement of living standards has afforded people the time and energy to pay more attention to their health. Physical exercise can improve health in a variety of and interesting ways. However, high-intensity exercise consumes a large amount of energy and tends to induce post-exercise fatigue. Maximizing the benefits of exercise performance depends on the optimal balance between training and recovery, so as to prevent psychological and physical maladjustment caused by load training $(1,2)$. It is generally believed that promoting physical and psychological recovery after exercise can enable individuals to perform better in subsequent training or competitions and reduce the risk of injury. Therefore, various rehabilitation interventions have been used to promote post-exercise recovery.

Exercise releases factors, such as creatine kinase (CK), that are related to energy production and metabolism. CK is an enzyme that catalyzes the transfer of high-energy phosphate bonds between adenosine triphosphate and phosphocreatine; it is one of the key enzymes of energy metabolism in skeletal muscle cells (3) and has become one of the most studied enzymes in the current research on exercise biochemistry. The concentration of CK in the blood increases after high- or low-intensity exercise, which can lead to skeletal muscle injury and soreness (4). Meanwhile, a decrease in CK concentration in the blood can reflect a reduction in muscle injury and faster post-exercise recovery (5). In addition, after intense exercise, quick and effective restoration of blood lactate concentration (BLC) to a resting level is also critical for athletes to maintain good physical strength. Active post-exercise recovery can increase metabolic rate and systemic blood flow, thus promoting the clearance of BLC and accelerating lactate metabolism through oxidation and gluconeogenesis (6-8). It has been shown that a significant difference exists in the post-recovery situation between individuals who perform active recovery to eliminate BLA and those whose recovery is passive (9). For the recovery period after a competition, researchers have focused on how to apply effective methods to eliminate BLA to achieve rapid recovery of the body. These include active recovery measures, such as relaxation activities after exercise and active rest with moderateintensity exercise $(10,11)$.

Hydrotherapy is another effective method that can shorten recovery time, and has been increasingly used in the global field of competitive training. Cold water immersion after exercise can reduce muscle fatigue and pain, so it is frequently used for post-exercise recovery (12). Intermittent pneumatic compression (IPC) is another common method; it has the advantage of not requiring muscle tension while still being able to produce sufficient pressure for increasing venous and lymphatic drainage, thereby reducing swelling (13). Food supplementation, with items such as milk, carbohydrates, lipids, vitamins, and minerals, is another easy and effective way to achieve post-exercise recovery. Among these, milk contains whey and casein, which can increase muscle protein synthesis after exercise (14) while a high concentration of electrolytes can promote the recovery of body fluid after exercise (15).

To a certain extent, the above methods may increase heart rate, blood pressure, respiration, metabolism and cardiac output during exercise. Furthermore, they can reduce the activity and concentration of serum CK, thus reducing the fatigue of athletes after training. Additionally, lactate metabolism can be accelerated, thus improving delayed muscle soreness after training, and preventing exercise-induced muscle injury. The aim of this metaanalysis was to investigate the effects of post-exercise recovery methods on exercise-induced hormones and blood fatigue factors, and to compare the effects of different postexercise recovery methods on CK concentration and BLC.

We present the following article in accordance with the PRISMA reporting checklist (available at http://dx.doi. org/10.21037/apm-20-2409).

\section{Methods}

\section{Literature retrieval strategy}

PubMed, Web of Science, and Embase databases were queried to collect randomized controlled trials of postexercise recovery methods between the inception and July 2020. The search terms were as follows: ("post-exercise recovery" and "exercise recovery" and "after exercise") or ("exercise-induced hormone") or ("fatigue factor" and "perceived fatigue"). The references of the included literature were then reviewed to supplement the studies.

\section{Screening criteria}

The inclusion criteria were as follows: (I) randomized controlled studies on post-exercise recovery methods published in the English language; (II) healthy subjects receiving a recovery method to restore motor function after exercise; (III) at least one outcome measure of exercise- 
induced hormone (CK or other) reported; (IV) at least one outcome indicator of fatigue factor (lactate or other) reported.

The exclusion criteria were as follows: (I) semirandomized controlled trials or non-randomized controlled trials, animal experiments, studies on mechanism, case reports, reviews; (II) repeated literature or literature with insufficient data; (III) reports with no outcome measures; (IV) subjects with cardiovascular diseases such as coronary heart disease and hypertension or genetic diseases, which could affect the outcome.

\section{Interventions and outcome measures}

The interventions were as follows: in the study group, cold water immersion, food supplementation, or IPC were applied as active post-exercise recovery methods; in the control group, passive post-exercise recovery, with no active measures, was applied.

The outcome measures were as follows: BLC and CK concentration in blood during post-exercise recovery.

\section{Data extraction}

Two investigators independently screened literature and extracted the data according to the screening criteria. Disagreements were resolved through discussion or consultation with a third party. The following data were extracted: name of the first author, year of publication, study location, interventions in the experiments, and main outcome measures.

\section{Quality evaluation}

Methodological quality of the included literature was evaluated using the method recommended by the Cochrane Handbook for Systematic Reviews of Interventions (16). The evaluation criteria for study quality included the following: whether random allocation was applied, whether the allocation scheme was concealed, whether a blind method was used, whether withdrawal and loss to followup were recorded, and whether intention-to-treat analysis was performed in cases of withdrawal and loss to follow-up. If all the quality evaluation criteria were fully met (i.e., yes), the study had the least risk for bias (level A); if one or more of the quality evaluation criteria were partially met (i.e., unclear), the study had a moderate risk for bias (level B); if one or more of the quality evaluation criteria were not met at all (i.e., no), the study had a high risk for bias (level C).

\section{Statistical analysis}

Stata (version 15.0) software was used for statistical analysis. For quantitative data, the combined effect size estimates were the standardized mean difference (SMD) and its 95\% confidence interval (CI). For dichotomous data, combined estimates were relative risk (RR) and its $95 \%$ CI. The study group (active post-exercise recovery) was compared to the control group (passive post-exercise recovery). Heterogeneity of the included studies were assessed using the Cochrane's $\mathrm{Q}$ test and $\mathrm{I}^{2}$ statistics. If homogeneity was significant $\left(\mathrm{P}>0.1, \mathrm{I}^{2}<50 \%\right)$, the fixed effects model (FEM) was used for meta-analysis; otherwise, the random effects model was used $\left(\mathrm{P}<0.05, \mathrm{I}^{2}>50 \%\right)$. Potential publication bias was evaluated using funnel plots, and sensitivity analysis of the study results was performed to assess the robustness of the conclusions.

\section{Results}

\section{Literature retrieval results and basic characteristics of the included literature}

A total of 488 potentially relevant studies were initially retrieved, and 401 were excluded according to titles and abstracts. After further filtering, 12 animal experiments, 54 unrelated studies, and 11 case reports were excluded. Finally, 10 trials (17-26) were included in this meta-analysis (Figure 1). In the study group, athletes received cold water immersion, food supplementation, and IPC as recovery measures after exercise. Among the included literature, seven articles carried out the comparison of cold water immersion and passive recovery, two articles compared food supplementation and passive recovery, and one article compared IPC and passive recovery. A total of 278 cases were involved in the 10 studies, of which 148 were assigned as the test group and 130 as the control group. The basic characteristics of all included literature are shown in Table 1. In general, the included trials were classified as low to moderate quality. The risk of bias of each trial is summarized in Figure 2.

\section{Meta-analysis results}

Effect of active and passive recovery on post-exercise recovery

Among the included literature, seven studies used cold 


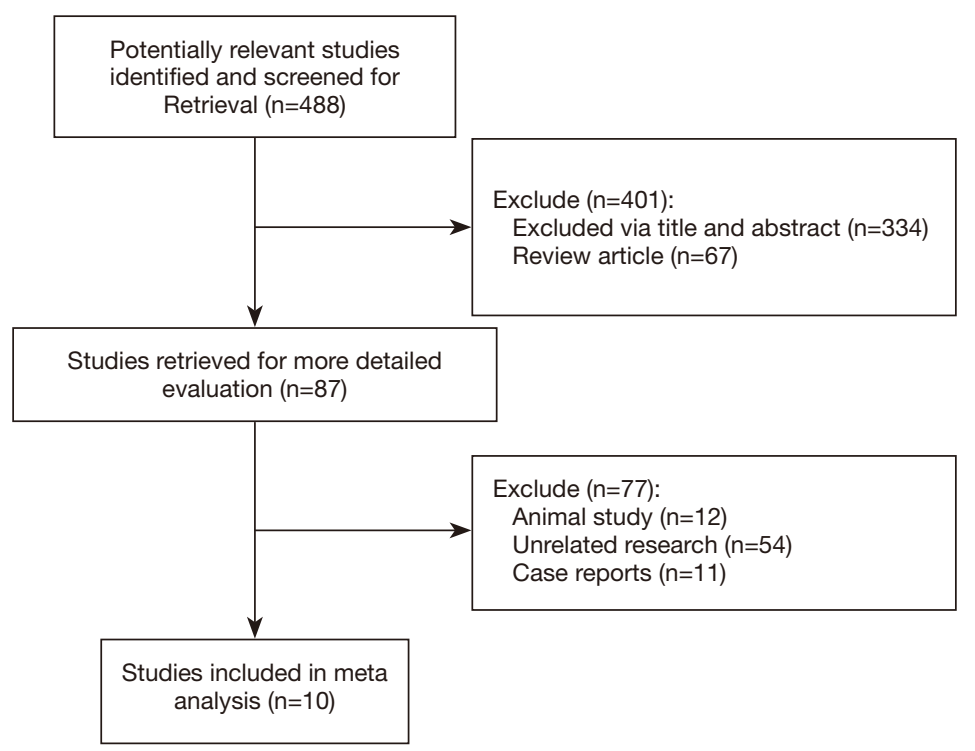

Figure 1 Literature screening process.

Table 1 The basic characteristics of inclusion in the literature

\begin{tabular}{lcccccc}
\hline First author & Year & Sex & Age & Sample size/case & Intervention measures & Outcome \\
\hline Llion A. Roberts & 2015 & Man & $21.2 \pm 2.2$ & 24 & CWI & CK \\
Giuseppe Banfi & 2008 & Man & $26 \pm 2.5$ & 20 & CWI & CWI \\
J. Vaile & 2007 & Man & $32.2 \pm 4.3$ & 24 & CWI & BLC \\
F. N. Bastos & 2012 & Man & $21 \pm 2$ & 40 & 63 & CWI \\
Franciele M. Vanderlei & 2017 & Man & $21.77 \pm 2.99$ & 17 & CWI & CWI \\
Paula Fernandes Aguiar & 2016 & Man & $23 \pm 3$ & 18 & 20 & CKC \\
Jonathan M. Peake & 2017 & Man & $22.1 \pm 2.2$ & 16 & Food \\
$\begin{array}{l}\text { D. J. Cochrane } \\
\text { Cindy Romain }\end{array}$ & 2013 & Man & $21.0 \pm 1.7$ & 20 & 36 & Food \\
Paula Rankin & 2017 & Man & Woman & $21.6 \pm 3.4$ & CK & CK \\
\hline
\end{tabular}

CWI, cold water immersion; IPC, intermittent pneumatic compression; CK, creatine kinase; BLC, blood lactate concentration.

water immersion as the post-exercise recovery method; Random effects models (REM) $\left(\mathrm{I}^{2}=83.6 \%, \mathrm{P}<0.001\right)$ was used for analysis, and a significant difference was identified between cold water immersion and passive recovery $(\mathrm{RR}=13.79 ; 95 \% \mathrm{CI}: 1.80,105.53, \mathrm{P}<0.001)$. In two studies, food supplementation was used as the post-exercise recovery method, REM was used for analysis, and no significant difference between food supplementation and passive recovery was found ( $\mathrm{RR}=23.52 ; 95 \% \mathrm{CI}: 3.41$, $162.15, \mathrm{P}>0.05)$. In one study, IPC was compared with passive recovery ( $\mathrm{RR}=21.00,95 \% \mathrm{CI}: 1.40,315.98)$. These results reveal that cold water immersion has a positive effect on post-exercise recovery compared with passive recovery (Figure 3).

Effect of active and passive post-exercise recovery on CK concentration and BLC

A total of seven articles explored the effect of post-exercise recovery methods on CK; REM $\left(\mathrm{I}^{2}=80.5 \%, \mathrm{P}<0.001\right)$ was used for analysis, and the results showed that within 


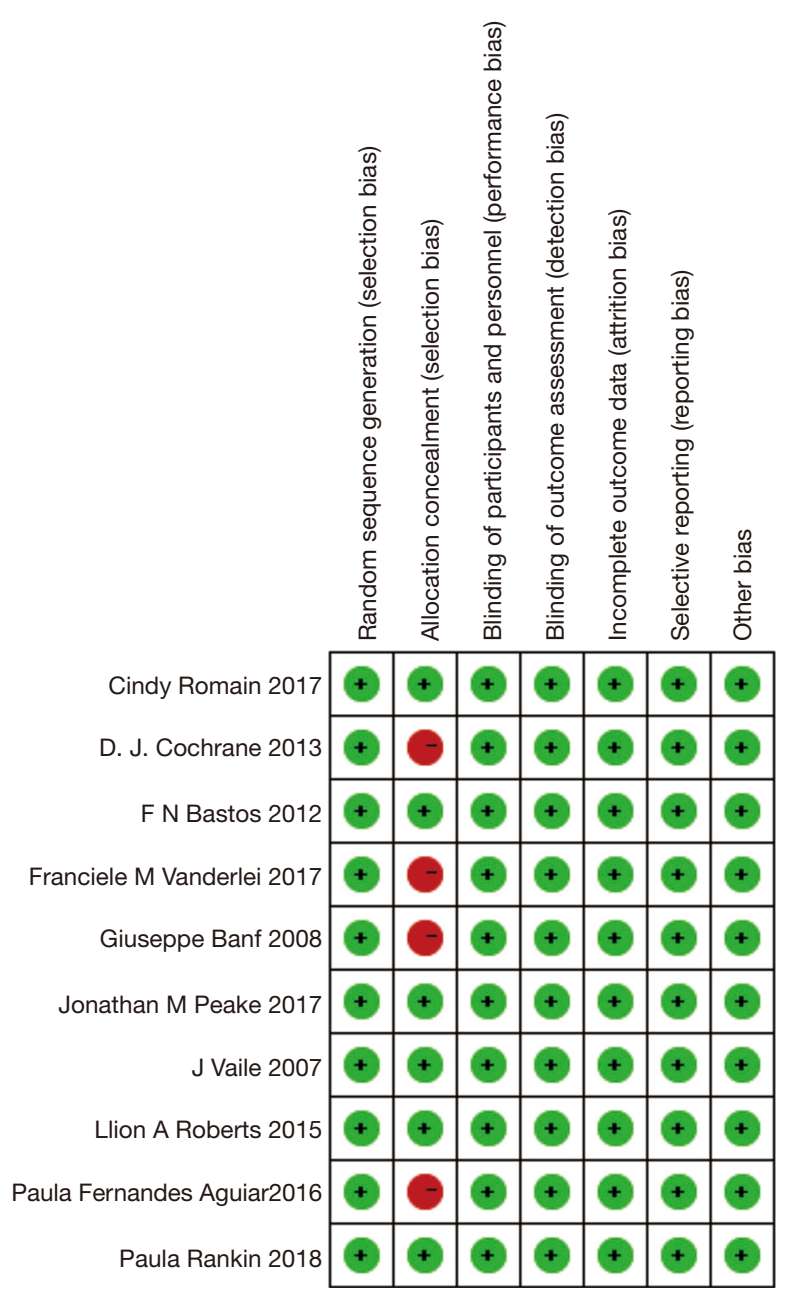

Figure 2 Risk of bias assessment of the included literature.

the same time, CK concentration was significantly lower after active post-exercise recovery measures than after passive recovery without any measures ( $\mathrm{SMD}=-0.76,95 \%$ CI: $-1.47,-0.04, \mathrm{P}<0.001)$. A total of three included articles investigated the effect of post-exercise recovery methods on BLC; $\operatorname{REM}\left(\mathrm{I}^{2}=78.0 \%, \mathrm{P}=0.011\right)$ was used, and results show that within the same time, BLC was significantly lower after active post-exercise recovery measures than after passive recovery $(\mathrm{SMD}=-1.16,95 \% \mathrm{CI}:-2.30,-0.02, \mathrm{P}=0.011)$ (Figure 4).

\section{Effect of different post-exercise recovery methods on CK concentration and BLC}

The subgroup analysis of different recovery methods with different outcome measures reviewed four studies that explored the effect of cold water immersion on CK concentration; the FEM $\left(\mathrm{I}^{2}=25.6 \%, \mathrm{P}=0.258\right)$ was applied, and the results showed no significant differences in CK concentration after receiving cold water immersion after exercise compared with passive recovery $(\mathrm{SMD}=-0.92$, 95\% CI: $-1.37,-0.47, \mathrm{P}=0.258$ ). Two studies investigated the effect of food supplementation on CK concentration; the REM $\left(\mathrm{I}^{2}=94.6 \%, \mathrm{P}<0.001\right)$ was used, and the results showed that food supplementation after exercise had some effect on the reduction of CK concentration $(\mathrm{SMD}=-1.16$, 95\% CI: $-4.69,2.36, \mathrm{P}<0.001)$. One study investigated the effect of IPC on CK concentration compared with passive recovery. As too few studies were eligible for this analysis, no statistical significance was identified. Cold water immersion was selected as the study group in three studies to observe its effect on BLC blood lactic acid concentration; $\operatorname{REM}\left(\mathrm{I}^{2}=78.0 \%, \mathrm{P}=0.011\right)$ was used, and the results showed that BLC was significantly decreased after receiving cold water immersion after exercise (SMD $=-1.16,95 \%$ CI: $-2.30,-0.02, \mathrm{P}=0.011$ ) (Figure 5).

\section{Publication bias}

Funnel plots were used to detect the publication bias in the multivariate meta-analysis. The effects of active passive recovery on CK concentration and BLC were compared (Figure 6). The funnel plot of the comparison was almost symmetrical, suggesting no significant publication bias and indicating that our results were stable and reliable.

\section{Sensitivity analysis}

The sensitivity analysis of active recovery and passive recovery effects on CK concentration, BLC, and other indicators (Figure 7) showed that after excluding one study at a time, the overall effect size of the other studies did not change greatly, indicating that these results were robust.

\section{Discussion}

This study investigated the effects of cold water immersion, food supplementation, and IPC as post-exercise recovery methods. The effects of post-exercise recovery methods on blood fatigue factor and exercise-induced hormone concentration, specifically the changes of $\mathrm{CK}$ concentration and BLC, were systematically compared. In addition, the effects of different post-exercise recovery methods on CK concentration and BLC were explored. In this study, we determined that taking certain recovery measures after 


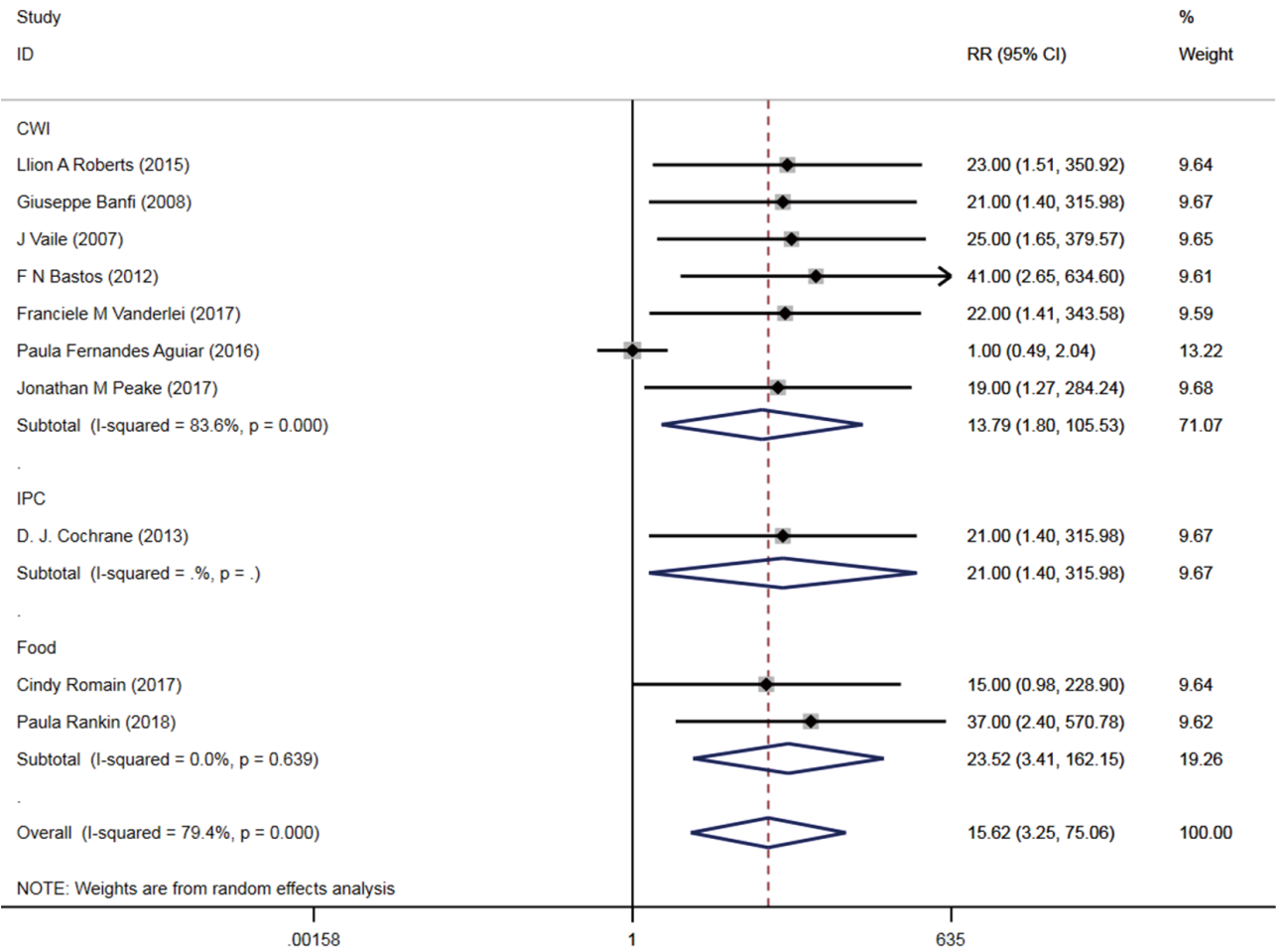

Figure 3 Forest plot of the comparison of active and passive recovery.

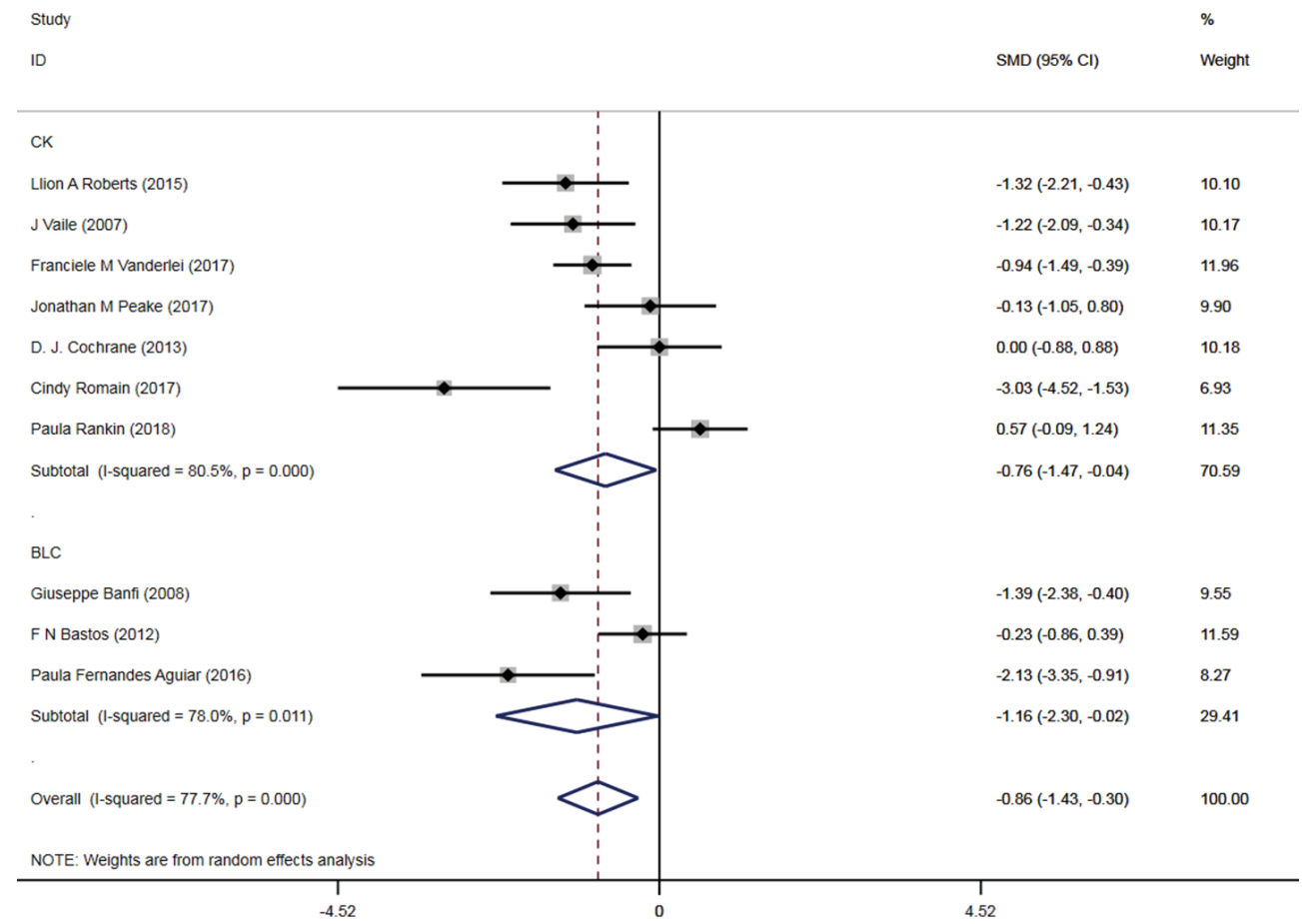

Figure 4 Forest plot of the comparison of the effect of active and passive recovery on CK concentration and BLC. CK, creatine kinase; BLC, blood lactate concentration. 


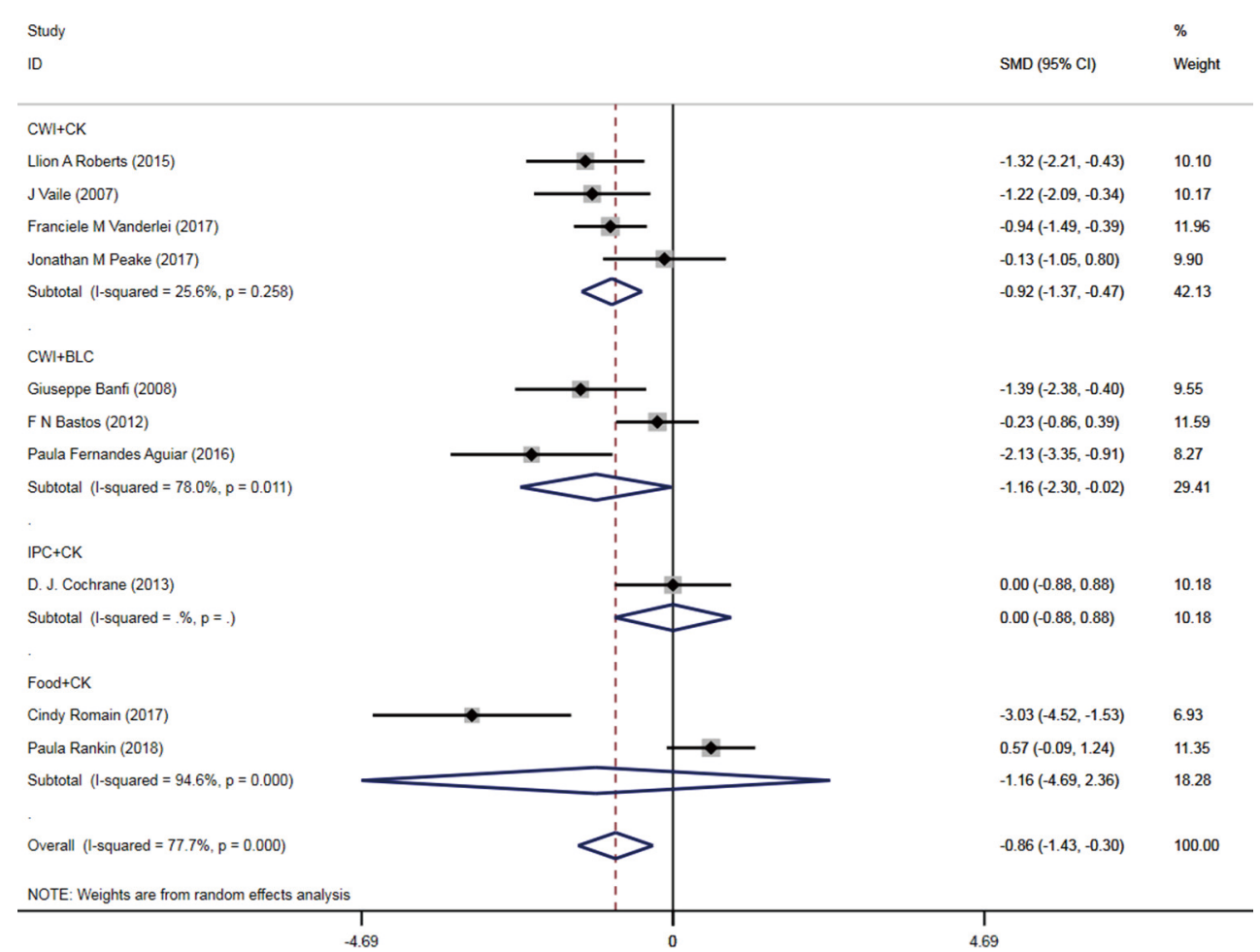

Figure 5 Forest plot of the effect of different recovery methods on CK concentration and BLC. CK, creatine kinase; BLC, blood lactate concentration.

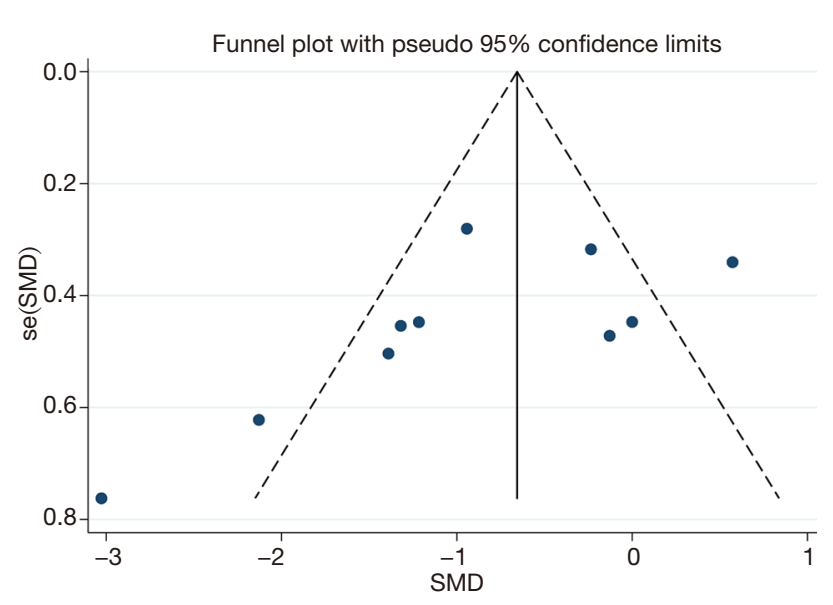

Figure 6 Funnel plot of the comparison of the effect of active and passive recovery on $\mathrm{CK}$ concentration and BLC. CK, creatine kinase; BLC, blood lactate concentration.

high-intensity exercise helps to reduce BLC and the activity and concentration of CK, thus accelerating the body's return to a pre-exercise state. Cold water immersion was the most effective among the three post-exercise recovery methods. The results of this meta-analysis showed that active recovery after exercise significantly reduced CK concentration and BLC compared with passive recovery, without significant publication bias. The results of the sensitivity analysis confirmed that these conclusions were also robust. In the analysis of the effects of different recovery methods on CK concentration and BLC, only cold water immersion had a statistically significant effect on the CK concentration, while sample size, food supplementation, and IPC had no effect.

Cold water immersion, as a common method for exercise recovery, has significant effects on both muscle soreness and perceived fatigue. It has been proven to have significant effects on post-exercise recovery when compared with passive recovery (27). CK concentration and BLC are common indicators in the studies of exercise fatigue (28). In the current meta-analysis, no significant changes were observed in the CK concentration in blood after cold water immersion, but BLC was reduced, which was beneficial to post-exercise recovery. Some related studies have also reported that the perceived fatigue scores were lower after cold water immersion (27). This study provides strong 


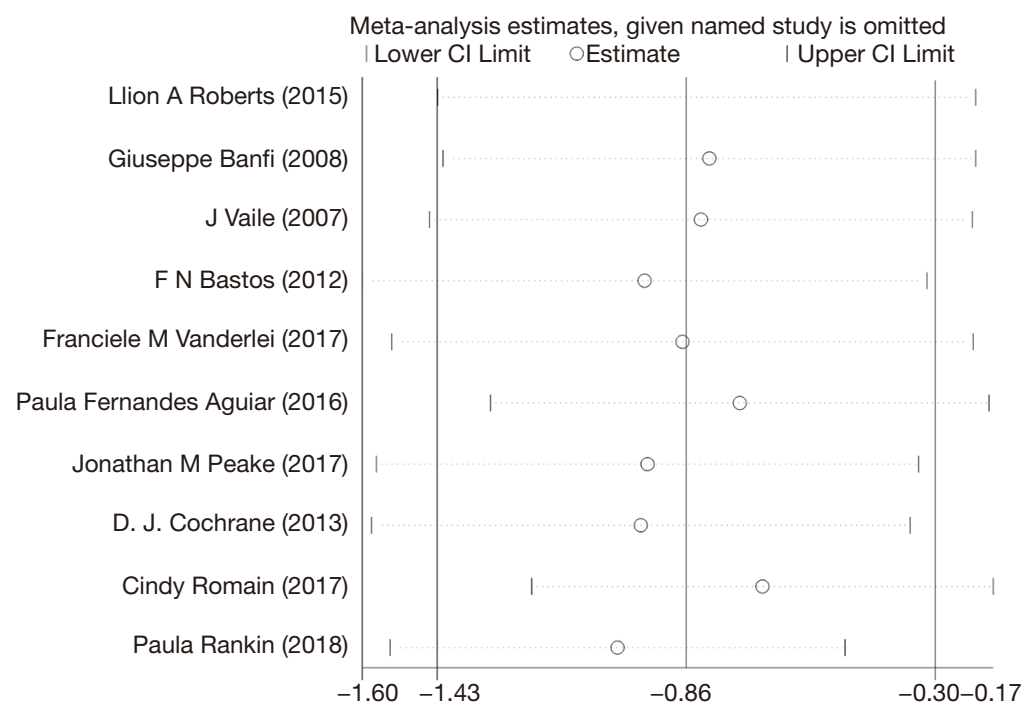

Figure 7 Sensitivity analysis of the comparison of the effect of active and passive recovery on CK concentration and BLC. CK, creatine kinase; BLC, blood lactate concentration.

evidence for the effect of cold water immersion on exercise recovery and BLC. However, the effects of cold water immersion on CK concentration in blood after exercise needs to be confirmed by further studies.

Food supplementation is the most convenient postexercise recovery method, but few studies have reported its potential to enhance recovery capacity during exercise. Studies have shown that after exercise which induces muscle injury, drinking $500 \mathrm{~mL}$ of milk can reduce the decline of muscle function, including peak torque, reactive strength index (RSI), and sprint performance $(29,30)$. This finding is valuable for nutritional prescription of athletes after exercise. In this meta-analysis, food supplementation was found to reduce CK concentration in the blood to some extent, thus accelerating the physical recovery after exercise. Increased levels of myoglobin and CK in the blood circulation are also markers of induced muscle injury after exercise (31). Therefore, the results of this study have potential value to evaluate the effect of food supplementation on injuries after exercise.

Our meta-analysis was limited by the small number of studies included, and only two studies on food supplementation and one study on IPC were eligible.

In summary, active recovery measures after highintensity exercise can accelerate the body's return to a preexercise state, and various recovery measures can change the concentration of CK and lactate in the blood. In this study, cold water immersion was demonstrated to be the best post- exercise recovery method. Considering the limitations, a better research design with a larger range of high-quality randomized controlled trials is still required to confirm the conclusions of this study.

\section{Acknowledgments}

Funding: This research is provided by Liaoning Province Innovative talents Projects (No. WR2019024).

\section{Footnote}

Reporting Checklist: The authors have completed the PRISMA reporting checklist. Available at http://dx.doi. org/10.21037/apm-20-2409

Conflicts of Interest: All authors have completed the ICMJE uniform disclosure form (available at http://dx.doi. org/10.21037/apm-20-2409). The authors have no conflicts of interest to declare.

Ethical Statement: The authors are accountable for all aspects of the work in ensuring that questions related to the accuracy or integrity of any part of the work are appropriately investigated and resolved.

Open Access Statement: This is an Open Access article distributed in accordance with the Creative Commons 
Attribution-NonCommercial-NoDerivs 4.0 International License (CC BY-NC-ND 4.0), which permits the noncommercial replication and distribution of the article with the strict proviso that no changes or edits are made and the original work is properly cited (including links to both the formal publication through the relevant DOI and the license). See: https://creativecommons.org/licenses/by-nc-nd/4.0/.

\section{References}

1. Meeusen R, Duclos M, Foster C, et al. Prevention, diagnosis, and treatment of the overtraining syndrome: joint consensus statement of the European College of Sport Science and the American College of Sports Medicine. Med Sci Sports Exerc 2013;45:186-205.

2. Soligard T, Schwellnus M, Alonso JM, et al. How much is too much? (Part 1) International Olympic Committee consensus statement on load in sport and risk of injury. $\mathrm{Br}$ J Sports Med 2016;50:1030-41.

3. Aujla RS, Patel R. Creatine Phosphokinase. 2020 Apr 26. In: StatPearls [Internet]. Treasure Island (FL): StatPearls Publishing, 2020.

4. Ertel KA, Hallam JE, Hillman AR. The effects of training status and exercise intensity on exercise-induced muscle damage. J Sports Med Phys Fitness 2020;60:449-55.

5. Hill J, Howatson G, van Someren K, et al. Compression garments and recovery from exercise-induced muscle damage: a meta-analysis. Br J Sports Med 2014;48:1340-6.

6. Rontoyannis GP. Lactate elimination from the blood during active recovery. J Sports Med Phys Fitness 1988;28:115-23.

7. Gollnick PD, Bayly WM, Hodgson DR. Exercise intensity, training, diet, and lactate concentration in muscle and blood. Med Sci Sports Exerc 1986;18:334-40.

8. Brooks GA. The lactate shuttle during exercise and recovery. Med Sci Sports Exerc 1986;18:360-8.

9. Plet J, Pedersen PK, Jensen FB, et al. Increased working capacity with hyperoxia in humans. Eur J Appl Physiol Occup Physiol 1992;65:171-7.

10. Beneke R, Leithäuser RM, Hütler M. Dependence of the maximal lactate steady state on the motor pattern of exercise. Br J Sports Med 2001;35:192-6.

11. Beneke R, Hütler M, Jung M, et al. Modeling the blood lactate kinetics at maximal short-term exercise conditions in children, adolescents, and adults. J Appl Physiol (1985) 2005;99:499-504.

12. Versey NG, Halson SL, Dawson BT. Water immersion recovery for athletes: effect on exercise performance and practical recommendations. Sports Med 2013;43:1101-30.

13. Partsch $\mathrm{H}$. Intermittent pneumatic compression in immobile patients. Int Wound J 2008;5:389-97.

14. Wilkinson SB, Tarnopolsky MA, Macdonald MJ, et al. Consumption of fluid skim milk promotes greater muscle protein accretion after resistance exercise than does consumption of an isonitrogenous and isoenergetic soyprotein beverage. Am J Clin Nutr 2007;85:1031-40.

15. Desbrow B, Jansen S, Barrett A, et al. Comparing the rehydration potential of different milk-based drinks to a carbohydrate-electrolyte beverage. Appl Physiol Nutr Metab 2014;39:1366-72.

16. Higgins JPT, Thomas J, Chandler J, et al. Cochrane Handbook for Systematic Reviews of Interventions. 2nd Edition. Chichester (UK): John Wiley \& Sons, 2019.

17. Roberts LA, Raastad T, Markworth JF, et al. Post-exercise cold water immersion attenuates acute anabolic signalling and long-term adaptations in muscle to strength training. J Physiol 2015;593:4285-301.

18. Banfi G, Melegati G, Barassi A, et al. Effects of wholebody cryotherapy on serum mediators of inflammation and serum muscle enzymes in athletes. Journal of Thermal Biology 2009;34:55-9.

19. Vaile J, Halson S, Gill N, et al. Effect of hydrotherapy on recovery from fatigue. Int J Sports Med 2008;29:539-44.

20. Bastos FN, Vanderlei LC, Nakamura FY, et al. Effects of cold water immersion and active recovery on post-exercise heart rate variability. Int J Sports Med 2012;33:873-9.

21. Vanderlei FM, de Albuquerque MC, de Almeida AC, et al. Post-exercise recovery of biological, clinical and metabolic variables after different temperatures and durations of cold water immersion: a randomized clinical trial. J Sports Med Phys Fitness 2017;57:1267-75.

22. Aguiar PF, Magalhães SM, Fonseca IA, et al. Postexercise cold water immersion does not alter high intensity interval training-induced exercise performance and Hsp72 responses, but enhances mitochondrial markers. Cell Stress Chaperones 2016;21:793-804.

23. Peake JM, Roberts LA, Figueiredo VC, et al. The effects of cold water immersion and active recovery on inflammation and cell stress responses in human skeletal muscle after resistance exercise. J Physiol 2017;595:695-711.

24. Cochrane DJ, Booker HR, Mundel T, et al. Does intermittent pneumatic leg compression enhance muscle recovery after strenuous eccentric exercise? Int J Sports Med 2013;34:969-74.

25. Romain C, Freitas TT, Martínez-Noguera FJ, et al. Supplementation with a Polyphenol-Rich Extract, 
TensLess(®), Attenuates Delayed Onset Muscle Soreness and Improves Muscle Recovery from Damages After Eccentric Exercise. Phytother Res 2017;31:1739-46.

26. Rankin P, Landy A, Stevenson E, et al. Milk: An Effective Recovery Drink for Female Athletes. Nutrients 2018;10:228.

27. Bleakley C, McDonough S, Gardner E, et al. Cold-water immersion (cryotherapy) for preventing and treating muscle soreness after exercise. Cochrane Database Syst Rev 2012;2012:CD008262.

28. Connolly DA, Sayers SP, McHugh MP. Treatment and prevention of delayed onset muscle soreness. J Strength

Cite this article as: Gu P, Zhang L, Zheng X, Zhang X. Effects of post-exercise recovery methods on exercise-induced hormones and blood fatigue factors: a systematic review and meta-analysis. Ann Palliat Med 2021;10(1):184-193. doi: 10.21037/apm-20-2409
Cond Res 2003;17:197-208.

29. Cockburn E, Hayes PR, French DN, et al. Acute milkbased protein-CHO supplementation attenuates exerciseinduced muscle damage. Appl Physiol Nutr Metab 2008;33:775-83.

30. Rankin P, Stevenson E, Cockburn E. The effect of milk on the attenuation of exercise-induced muscle damage in males and females. Eur J Appl Physiol 2015;115:1245-61.

31. Brancaccio P, Lippi G, Maffulli N. Biochemical markers of muscular damage. Clin Chem Lab Med 2010;48:757-67.

(English Language Editors: L. Gray and J. Gray) 